\title{
EFEITO DA ICTERÍCIA OBSTRUTIVA NA CICATRIZAÇÃO DE ANASTOMOSES COLÔNICAS EM RATOS ${ }^{1}$
}

\author{
THE EFFECT OF THE OBSTRUCTIVE JAUNDICE \\ ON HEALING OF COLONIC ANASTOMOSES IN RATS
}

\author{
Marcelo Almeida Azevedo ${ }^{2}$ \\ Omar Féres $^{3}$ \\ José Joaquim Ribeiro da Rocha ${ }^{3}$ \\ Francisco Aprilli ${ }^{3}$ \\ Antonio Dorival Campos ${ }^{4}$ \\ Ricardo dos Santos Garcia ${ }^{5}$
}

\section{RESUMO}

Introdução - A deiscência de anastomoses é uma das complicações que ocorre em pós-operatórios de cirurgias do aparelho digestivo, aumentando a morbimortalidade de pacientes. No cólon, particularmente, essa complicação tem maior gravidade pela presença de fezes dentro da cavidade peritoneal, o que pode levar a peritonites críticas. Objetivo - Avaliar a cicatrização de anastomoses colônicas em ratos na vigência de icterícia obstrutiva. Métodos - Foram utilizados 23 ratos divididos em dois grupos. Grupo I (controle): $\mathrm{n}=10 \mathrm{e}$ Grupo II (obstruído): $\mathrm{n}=13$. No início do experimento foram realizadas ligadura e secção do colédoco. Após sete dias, realizados secção e rafia do cólon distal. No $14^{\circ}$ dia de experimento avalia-se condição local da cavidade e resseca-se segmento da anastomose para estudo bioquímico. No grupo II ou Controle $(\mathrm{n}=10)$ apenas não se realiza a ligadura de colédoco obedecendo todas as outras condições do grupo I. Resultados Foi observado maior número de complicações no grupo Obstruído (4/13) do que no Grupo Controle (0/10), mas que foi sem significância estatística e também que a variância dos valores da dosagem de hidroxiprolina no grupo Obstruído foi maior que no grupo Controle mesmo apresentando média de valores semelhantes estatisticamente.
Descritores - anastomose colônica, icterícia obstrutiva, cicatrização. Disponível em URL: http:// www.scielo.br/acb

\begin{abstract}
The objective is evaluation of the effect of obstructive jaundice on healing of colonic anastomosis in rats. It was observed more complications such as anastomoses dehiscences and deaths $(4 / 13) \times(0 / 10)$ in the obstructed group. There was no statistical difference in the concentrations of hidroxyproline on groups.
\end{abstract}

Key Words - Colonic anastomoses, healing, obstructive jaundice.

\section{INTRODUÇÃO}

A deiscência de anastomoses colônicas é uma complicação importante em pós-operatórios de cirurgias do aparelho digestivo, aumentando a morbi-mortalidade de pacientes ${ }^{1}$.

No cólon, particularmente, esta complicação tem maior gravidade pela presença de fezes em cavidade peritoneal levando a peritonites críticas. Em condições ideais, uma anastomose deve ser bem vascularizada, realizada sem tensão e livre de contaminação bacteriana ${ }^{2,3}$.

1 Trabalho realizado no Laboratório de Técnica Cirúrgica e Cirurgia Experimental do Departamento de Cirurgia e Anatomia da Faculdade de Medicina de Ribeirão Preto da Universidade de São Paulo - FMRP-USP.

2 Aluno do sexto ano médico da Faculdade de Medicina de Ribeirão Preto - FMRP-USP.

3 Docente da Disciplina de Coloproctologia do Departamento de Cirurgia e Anatomia da FMRP-USP

4 Docente do Departamento de Medicina Social da FMRP-USP

5 Pós-graduando do Departamento de Cirurgia e Anatomia da FMRP-USP

106 - Acta Cirúrgica Brasileira - Vol 17 (Suplemento 3) 2002 
Vários são estudos a respeito de condições que possam interferir na freqüência das deiscências de anastomoses colônicas, como fatores inerentes à técnica cirúrgica, condições locais, uso de agentes farmacológicos e condições gerais do paciente ${ }^{4,5}$.

Certas condições gerais podem prejudicar o processo de cicatrização, tais como hipotensão arterial, hipovolemia, isquemia intestinal, baixa tensão de oxigênio, neoplasia maligna avançada, desnutrição, desidratação, uremia e idade avançada do paciente ${ }^{6,7,8}$. Existem relatos de que a icterícia pode levar ao aumento das deiscências de parede abdominal, no entanto há poucos relatos quanto à influência da icterícia interferindo nas anastomoses colônicas ${ }^{9,10}$.

Em algumas situações, é necessário realização de cirurgias com anastomose colônica, em pacientes portadores de icterícia por diversas razões, tais como coledocolitíase, hepatopatia crônica e cirrose hepática. Essa é uma situação angustiante para o cirurgião, motivandonos a realizar este trabalho para testar a influência da icterícia na cicatrização de anastomoses colônicas.

O objetivo deste estudo científico experimental é avaliar a cicatrização de anastomoses colônicas em ratos na vigência de icterícia obstrutiva (colestase).

\section{MÉTODOS}

Foram utilizados 23 ratos machos Wistar distribuídos em dois grupos: Grupo I (controle): 10 ratos e Grupo II (obstruído): 13 ratos.
No início do experimento (D0), foram realizados laparotomia mediana superior, ligadura com Prolene ${ }^{\circledR}$ 5-0 e secção posterior de colédoco, e rafia de parede abdominal com Mononylon ${ }^{\circledR} 4-0^{11}$. No $7^{\circ}$ dia de experimento (D7), foram realizados laparotomia mediana inferior, secção segmentar do cólon a $3 \mathrm{~cm}$ da reflexão peritonial, confecção de anastomose colônica término-terminal com sutura contínua com fio Prolene ${ }^{\circledR}$ 6-0 e rafia da parede abdominal. Nesse período foram colhidos de dois $\mathrm{ml}$ de sangue para dosagem de enzimas hepáticas (TGO, TGP, gamaGT, fosfatase alcalina e bilirrubinas) em ambos os grupos ${ }^{11}$. No $14^{\circ}$ dia de experimento (D14) foi realizado sacrifício de todos os ratos (Grupos I e II), com avaliação macroscópica da anastomose colônica e da cavidade abdominal. Também foi colhido material da anastomose colônica para dosagem de hidroxiprolina. Com a mensuração desta estima-se o colágeno sintetizado pelo fibroblasto, servindo como um parâmetro bioquímico da avaliação cicatricial da anastomose colônica ${ }^{12}$.

\section{RESULTADOS}

Após análise dos resultados, observou-se que no início do experimento (D0) não houve diferença estatística entre os pesos dos Grupos I e II. No entanto, foi observada diferença estatística $(p<0,05)$ quando analisados os valores dos pesos entre os dois grupos no $07^{\circ}$ e $14^{\circ}$ dias do experimento, quando utilizado teste não-paramétrico (Mann-Whitney) corrigido pelas variâncias (Figura 1).

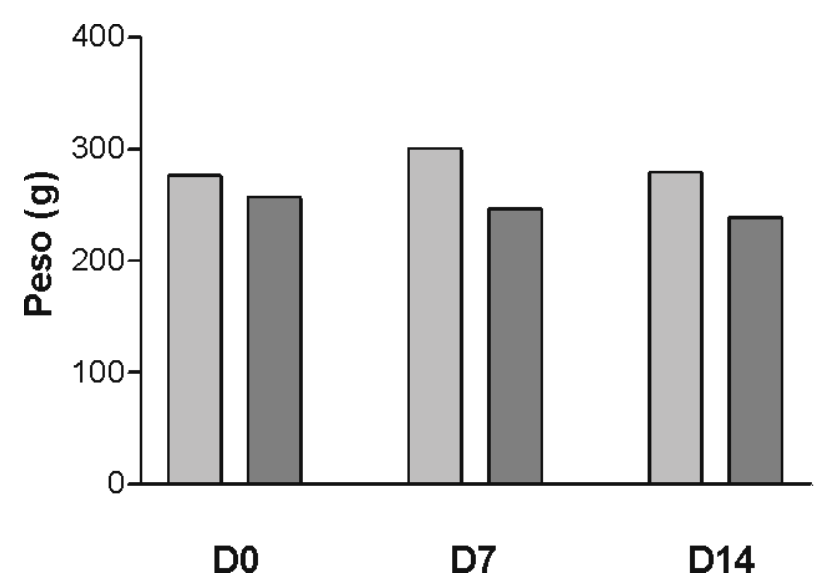

Figura 1 - Variação da média dos pesos em ambos os grupos.

Nos ratos do grupo II (obstruídos) confirmouse, no D7, icterícia clinicamente (colúria) e bioquimicamente pelas enzimas ALT, AST, gama GT, fosfatase alcalina e bilirrubinas $(\mathrm{p}<0,001)$. No grupo Controle não foi evidenciado alterações significativas de enzimas hepáticas ou colúria.
No grupo Controle, não foram observadas complicações como deiscência de anastomose colônica ou óbitos. Entretanto, no grupo Obstruído foram observadas as seguintes complicações: três deiscências de anastomose colônica, que evoluíram com obstrução colônica, ascite e peritonite e um único óbito. Não foi 
evidenciada diferença estatística quando utilizado teste nãoparamétrico para o número de complicações $(\mathrm{p}=0,10)$.

Foi colhido material da anastomose colônica no $14^{\circ}$ dia de experimento para avaliação bioquímica pela dosagem de hidroxiprolina de 10 ratos do grupo

Controle e 10 ratos do grupo Obstruído. Não foi possível colher material do rato que veio a óbito e de dois ratos evoluíram com deiscência de anastomose colônica. Os valores de hidroxiprolina não apresentaram diferença estatística entre os dois grupos (Figura 2).

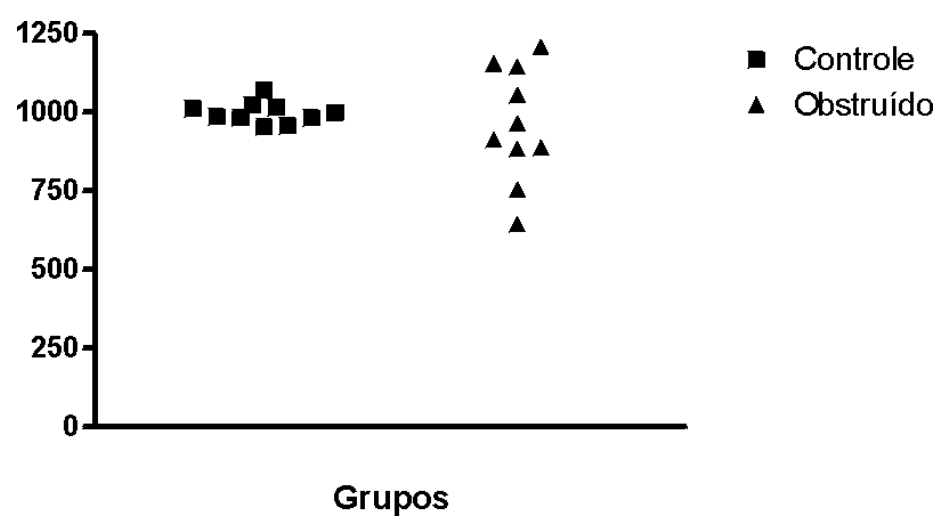

Figura 2 - Dosagem de hidroxiprolina, onde se evidencia variância significativa no grupo obstruído.

\section{DISCUSSÃO}

Observou-se, neste estudo, que a icterícia leva a um maior número de complicações totais como: deiscências de anastomose colônica e óbito $(4 / 13 \times 0 / 10)$ sem valor estatisticamente significativo. Foi também observado que os valores da dosagem de hidroxiprolina no grupo obstruído foi muito menos uniforme, e quando correlacionado com os resultados de que apenas alguns ratos evoluem com mau prognóstico, sugerem que a cicatrização sem complicações provavelmente segue o mesmo processo de síntese de colágeno, que no grupo controle. Estatisticamente foi observada maior variância na dosagem de hidroxiprolina no grupo Obstruído que no Grupo Controle apesar de os valores entre os grupos terem uma mediana sem valor de significância estatística.

\section{CONCLUSÃO}

Observou-se que a icterícia é um fator de grande impacto na evolução da cicatrização de anastomose colônica em ratos, pela diferença no número de complicações entre o grupo Controle e Obstruído. Acreditamos que a avaliação histopatológica (última etapa deste projeto) possa acrescentar na elucidação das alterações dos fenômenos reparativos na cicatrização das anastomoses colônicas em ratos icterícia obstrutiva.

\section{REFERÊNCIAS}

1. Bearhs $\mathrm{OH}$. Complications of colonic surgery. Surg Clin North Am 1967;47:983-8.
2. Debas HT, Thomson FB. A critical review of colectomy with anastomosis. Surg Gynecol Obstet 1972;135:747-52.

3. Halsted WS. Circular suture of the intestine: an experiment study. Am J Med Sci 1887;75:436-61.

4. Kerr HH. The development of intestinal surgery. JAMA $1923 ; 81: 641-7$.

5. Hendrix T, Mastboom WJB. Healing of experimental intestinal anastomoses. Parameters for repair. Dis Colon Rectum 1990;33:891-901.

6. Sheridan WG, et al, Tissue oxygen tension as a predictor of colonic anastomotic healing. Dis Colon Rectum 1973; 30:513-8.

7. Kologlu M, et al, Effect of persistently intraabdominal pressure on healing of colonic anastomoses. Am J Surg 1999;178(4): 293-7

8. Schrock TR et al. Factors contributing to leakage of colonic anastomoses. Ann Surg 1973;177:513-8.

9. Grande L, Garcia-Valdecasas JC, Fuster J, Visa J, Pêra C. Obstructive jaundice and wound healing. Br J Surg 1990;51(5):245-51. Review.

10. Irvin TT, et al. Abdominal wound healing in jaundice patients. Br J Surg 1978;65:521-2.

11. Castro e Silva Jr O, et al. Obstrução Biliar Extra-hepática. Modelos Experimentais em Cirurgia - Cap.15, p.191200,1998 .

12. Than $\mathrm{T}$, et al. Skin prolin hydroxylase in patients with obstructive jaundice. The Lancet 1974;5:807-8.

\section{Endereço para correspondência}

Omar Feres

Departamento de Cirurgia e Anatomia

Faculdade de Medicina de Ribeirão Preto - USP

Campus Universitário

14048-990 - Ribeirão Preto - SP

e-mail - 